\title{
The influence of panic activation through breath holding intervention towards QEEG of social bonding
}

\author{
Lisa Kurniawan ${ }^{*}$
}

University of Surabaya, Surabaya, Indonesia

\author{
Key Words: \\ Carbon dioxide \\ Panic \\ Breath holding \\ Social bonding \\ EEG
}

Received: 15 May 2016

Accepted: 29 May 2016

Published: 24 June 2016

\begin{abstract}
Many studies stated that carbon dioxide $\left(\mathrm{CO}_{2}\right)$ is connected with panic symptoms. The high level of $\mathrm{CO}_{2}$ inside the brain can stimulate the respiration system and the unstable balance of acid and base, which develops into panic symptoms. In this experiment, the researcher uses a breath holding intervention to increase the level of $\mathrm{CO}_{2}$. The high level of $\mathrm{CO}_{2}$ generates the production of endocrine and significant emotional reaction or behavior. The connection between the emotional function and the panic symptom prompted the researcher to underline the role of social contact inside individuals. Based on the researches, the sensitivity of social influences also affects future panic symptoms. The chosen variable related to social contact is social bonding. The social bonding variable will be formed into the photos of closer relatives and non-closer relatives to the subject. To measure and analyze data, the researcher uses QEEG (Quantitative Electroencephalography) to record the brain waves when the subject sees and feels the bonding through photos shown.
\end{abstract}

(C) 2016 The Author(s). Published by TAF Publishing.

\section{INTRODUCTION}

This research is trying to investigate the relation between panic emotion and social bonding. From the file of Indonesia Minister of Health, the prevalence of panic disorder in the world has a high rate of $13.8 \%$. Panic disorder in mental health topic can not be disregarded. Previous researches show that about $50 \%$ panic disorder patient suffer severe separation anxiety [1] or traumatic experience associated with bonding or separation.

La Pierre [2] state that the function of attachment relationship is very important in individual social needs. Disregulation organization between body-brain-thoughts can impact in serious mental and physical health implications in long term and also affect the instability of neuochemistry which has programmed according to human basic needs. Many studies highlighted the connection fact between attachment towards brain, immunity system, and psychosomatic disorder. Psychosomatic symptom commonly happens in the form of changes in heart rate, breathing, muscle tension, and temperature which are all come as the result of fundamental emotion processing.

Emotional and behavior function can be related with social contact. Mawson [3] said the sensitivity caused by social influences is described as the characteristic connected to panic symptom. [4, 5, 6, 7] reviewed by Mawson [3] also support the evidence that social influences have a role as the main key of panic symptom. Unwanted separation by the child

\footnotetext{
${ }^{*}$ Corresponding author: Lisa Kurniawan

†Email: lisakurniawan88@gmail.com
} 
from the parents which is happened from childhood to mid-adolescent can be defined as childhood parental loss (including death of parents, separation, divorce) can develop the risk of panic disorder in adulthood [9]. Separation and feeling loss is the key component of children separation anxiety. This hypothesis has long been disclosed by Klein [10], reviewed by Battaglia [9].

Many disadvantages factor resulting from panic disorder in relation to the life quality and work performance. Panic symptom related to neurotransmitter system which is produced by brainstem. The main system of neurotransmitter is norepinefrin, serotonin, dan Gamma-Aminobutyric Acid (GABA). Panic attack can last for minutes until hours and associated with a strong will to escape from the situation or location and even caused suicide.

To stimulate panic activation in this experiment, researcher use breath holding intervention. With breath holding intervention, the amount of carbon dioxide $\left(\mathrm{CO}_{2}\right)$ inside the brain will be increased then can stimulate panic activation to subjects. Freire et al. [11] also use two kinds of intervention to stimulate panic, such as $35 \% \mathrm{CO}_{2}$ challenge (exogenous) and breath holding (endogeneous). The sufficient $\mathrm{CO}_{2}$ in subject, shows the increasing of anxiety and panic attacks of patient with panic disorder.

Many studies concerning this relationship are using PET or Functional Magnetic Resonance Imaging (FMRI) to observe and measure the activity inside the brain. But on this study, researcher prefer use Quantitative Electroencephalography (QEEG) to observe and measure the neuron activity which can prove the influence of panic emotion towards social bonding.

\section{LITERATURE REVIEW}

Child is biologically programmed to establish attachment with the others in order to survive. Bonding is an attachment between mother and child or child and mother after the birth. Bonding influences long term attachment and develop emotional well-being. Bowlby et al. [12] believed that attachment behavior is obtained from insting and can be activated through threaten conditions, such as separation, insecurity, and also fears. Failed to establish an attachment is led to maternal deprivation which refers to separation or loss of mother role in life.

Panksepp [13] underlined that panic system is elaborated with social-emotional process connected to attachment. Panksepp [13] cites other research and stated that the loss in childhood is the main factor of depression and panic attack in the future. Panksepp [13] said that one of the caused of depression and panic attack is permanent modification from emotion associated with separation distress. Panic neocircuit associated with separation distress can occur from past painful memory recorded inside the brain.

According to Diagnostic and Statistical Manual of Mental Disorder IV (DSM IV) panic attack symptom can be described as: (1) palpitations, pounding heart, or accelerated heart rate; (2) sweating; (3) trembling or shaking; (4) sensations of shortness of breath or smothering; (5) feeling of choking; (6) chest pain or discomfort; (7) nausea or abdominal distress; (8) feeling dizzy, unsteady, lightheaded, or faint; (9) derealization (feelings of unreality) or depersonalization (being detached from oneself); (10) fear of losing control or going crazy; (11) fear of dying; (12) paresthesias (numbness or tingling sensations); (13) chills or hot flushes [14], [15], [16], [17] reviewed by Yaunin [18]. The point of panic disorder cognitive-behavioral model is the misinterpretation catasthropic experienced by patient at the situation or the somatic sensation which leads to the feelings of danger associated with panic attack [19], [20]. The somatic sensation developed by the patient as- 
sociated with panic attacks is part of body defense mechanism or alarm. Panic disorder patient have excessive respond to changes on carbon dioxide levels in the body. Klein [10] Freire et al. [21] suggests that panic attacks arise spontaneously when brain realize the suffocation false alarm system. This disfunction are marked by hypersensitivity respond of carbon dioxide in the body. Many studies suggest that respiratory system is the most powerful physiological signs to measure emotion $[22,23,24]$ reviewed by Kinkead et al. [25]. The reduction of oxygen or the raise of carbon dioxide can activate endocrine and emotion reaction or significant behavior.

There are two types of carbon dioxide stimuli, such as endegenous and exogenous. Endegenous is activated through breath holding technique, while exogenous is activated trough inhalation technique using $35 \%$ carbon dioxide. Breath holding intervention is used on this research. This results in a $\mathrm{CO}_{2}$ stimulus panic emotion which is affected by neurochemicals and neurotransmitter in the brain. Then measured by QEEG. The complete scheme as below:

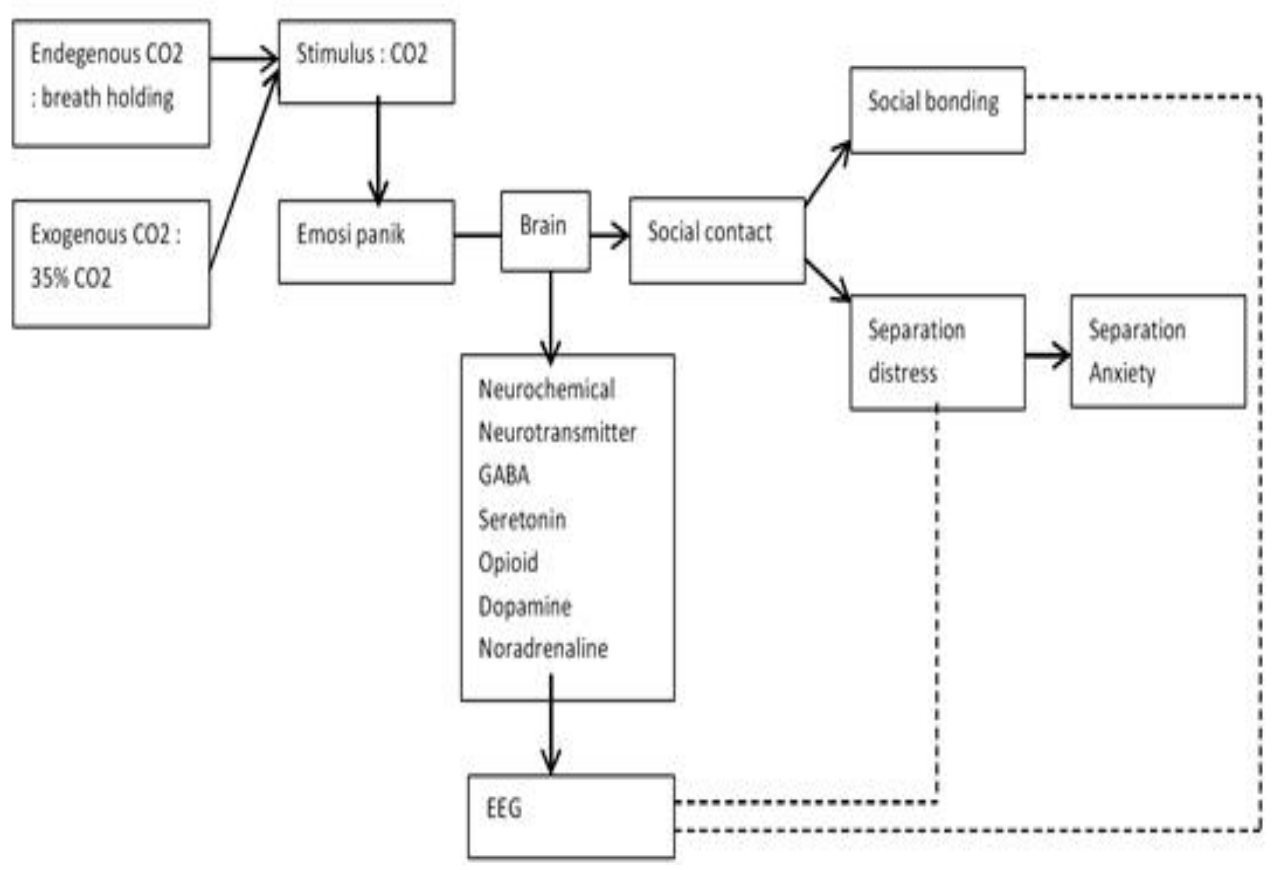

FIGURE 1. Scheme of the research

The results using QEEG or Electroencephalograhy is line tracing or can be referred as brain wave. Commonly, QEEG is used to diagnose brain damage, epilepsy, and neurological disorder. For applied research, QEEG is used to identify the activity pattern in the brain related to certain behavior.

\section{METHODOLOGY}

\section{Participants}

Method of research using experimental A-B design because researcher using single subject. Experiment method aims to measure the behavior target on baseline phase and intervention phase. Participants are women aged 16-38 years old. The subjects are selected through exclusion criteria: (1) psychiatric disorder in cognitive, afective, or personality; (2) use medication for psychiatric disorder; (3) have ever experienced trauma or injury on the head. 


\section{Tools}

Researcher use PSL (Panic Symptom List) Questionnaire with 13 items that screen for 13 panic symptoms with scale 1-4 (1 = do not feel anything, $4=$ heavy). Also ASI (Anxiety Sensitivity Index) with 16 items that screen for anxiety sensation which have negative psychologycal impact $[16,26]$. Previous study indicated that anxiety sensitivity associated with panic attack, and also closely related to agoraphobia $[27,16,26]$.

To measure how anxious or uncomfortable perceived by subjects, researcher using VAS (Visual Analog Scale). VAS is an instrument which try to measure characteristic or behavior and believed to lie at a value that cannot be measure directly and easily. Operationally VAS is a horizontal line with length of $100 \mathrm{~mm}$, and marked by word description in the end of each line. Subjects will give mark between the line to represent their perception at the moment. VAS score is determined by measuring the length of milimeter from left end into subject's mark point.

\section{Procedure}

\section{Pre-experiment phase}

In this phase, researcher do mini interview to screening the subjects related to gender, age, also the exclusion criteria which have been described above. Also researcher ask participants to fill in PSL, ASI, and VAS questionnaire. Then EEG Electrodes are mounted on subjects head. Subjects are asked not moving much to avoid misinterpretation in EEG result.
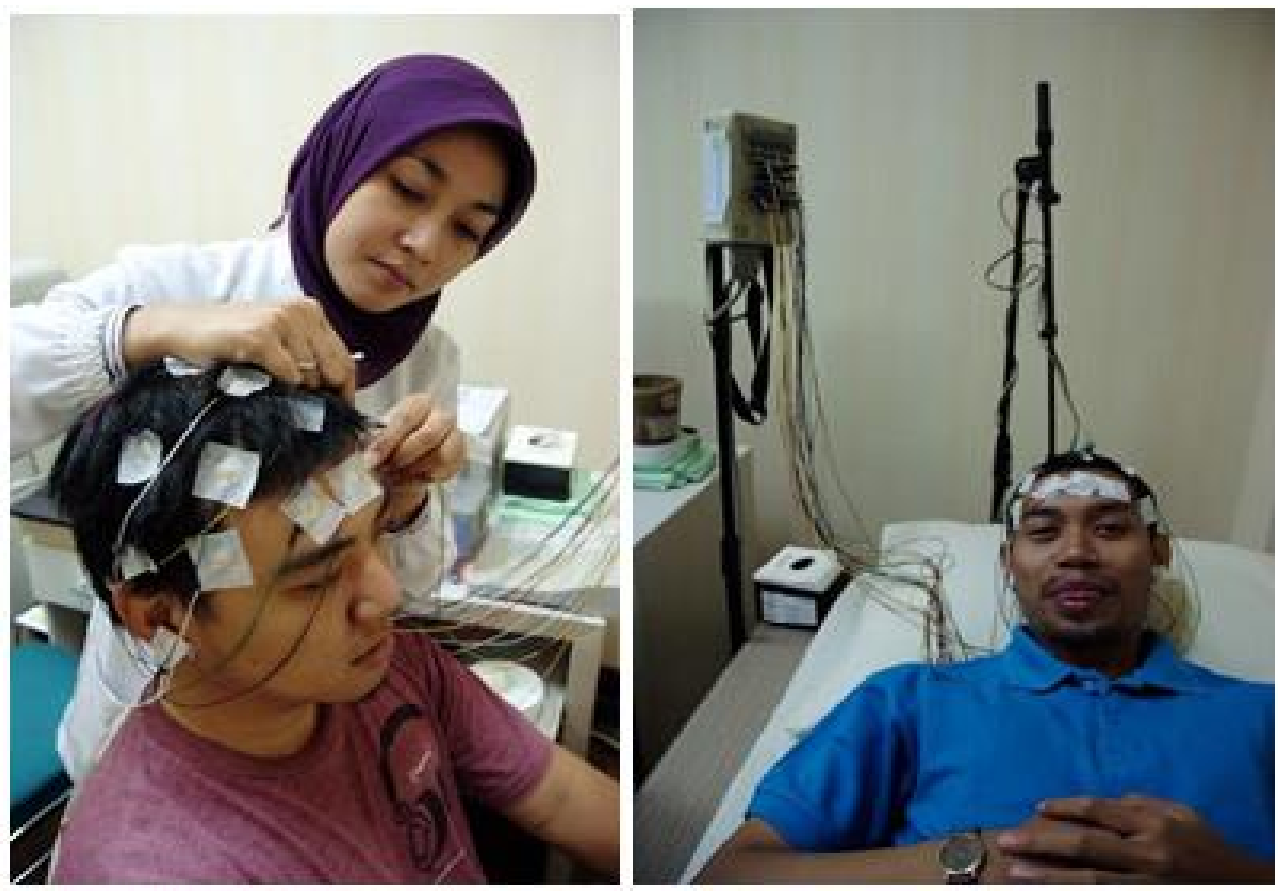

FIGURE 2 . EEG electrodes are mounted to the head

\section{Experimental phase}

Researcher prepare two kind of photos related to subjects relative, one kind is subject's close relative (family, best friend, spouse) and other kind is about subject's non-close relative (non-closer friend or non-closer relatives). Each kind (close and non-close relative) consist of 5 photos and display 10 seconds. Phases divided into two conditions, control condition and experiment condition. 
In control condition, subjects do resting state while subjects see the picture of close and non-close relative. Resting state means subjects don't have to do breath holding intervention. Total time need for resting state is 20 seconds. Then social bonding which subject feel is recorded through QEEG.

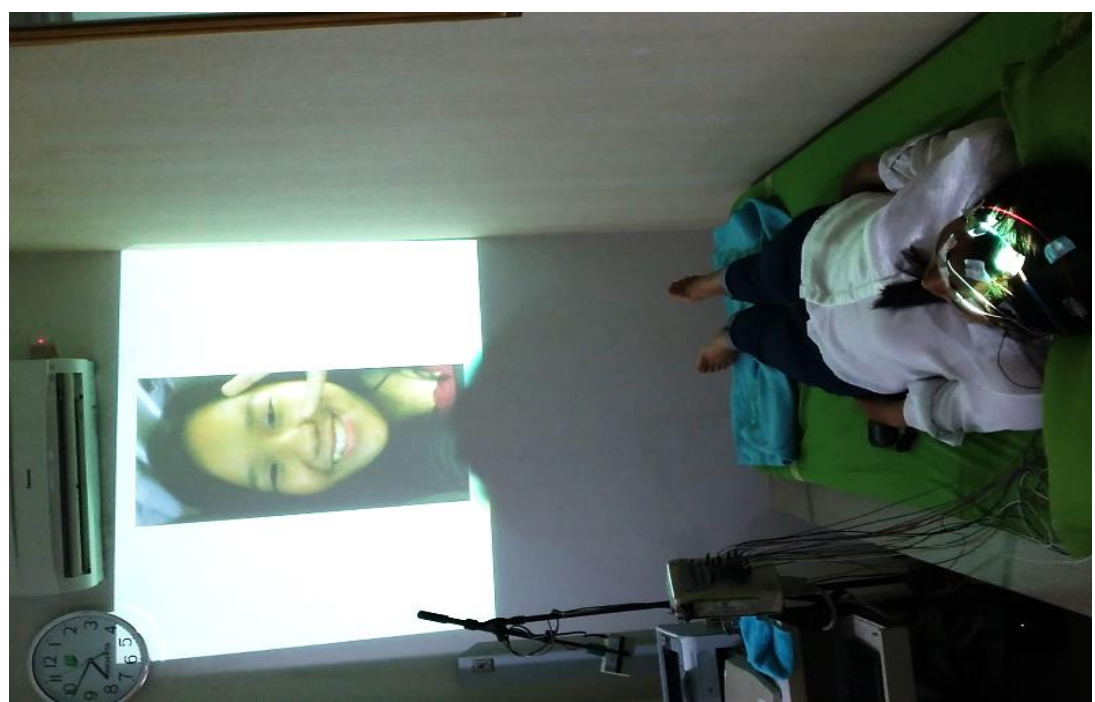

FIGURE 3 . Subjects see the photo of close relative

In experiment condition, subjects do breath holding intervention while subjects see the picture of close and non-close relative. Total time need for resting state is 20 seconds. Then social bonding which subject feel is recorded through QEEG. The experiment paradigm can be arranged as:

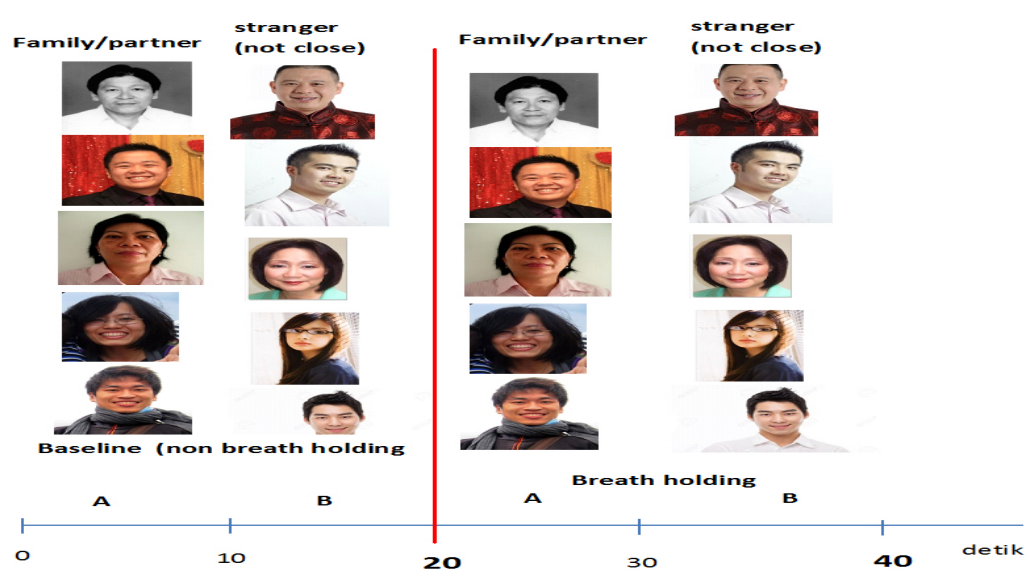

FIGURE 4 . Experimental paradigm

\section{Post-experiment phase}

Data collected from QEEG using EEG Brain Mapping Ceegraph IV Bio-Logic. Recorded area cover 21 channel which is: frontal pole (Fp1, Fpz, Fp2), frontal (F7, F3, Fz, F4, F8), central (C3, Cz, C4), temporal (T3, T4, T5, T6), parietal (P3, Pz, P4) and oksipital (01, Oz, O2). 

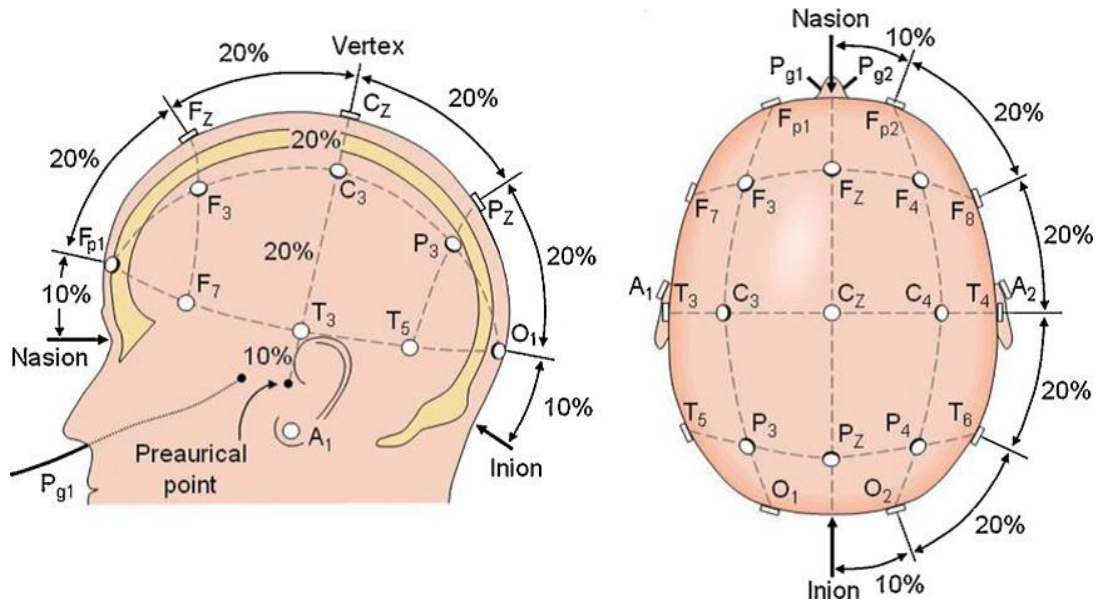

FIGURE 5 . Mounting points of EEG

TABLE 1. The results of experiment

\begin{tabular}{llc}
\hline \hline & Z & Asymp. Sig. (2-tailed) \\
\hline Fp1_BHSGNSB_Delta-Fp1_BHSGSB_Delta & $-.014 \mathrm{a}$ & 0.989 \\
Fp2_BHSGNSB_Delta-Fp2_BHSGSB_Delta & $-.754 \mathrm{a}$ & 0.451 \\
F3_BHSGNSB_Delta-F3_BHSGSB_Delta & $-1.828 \mathrm{~b}$ & 0.068 \\
F4_BHSGNSB_Delta-F4_BHSGSB_Delta & $-1.200 \mathrm{~b}$ & 0.230 \\
C3_BHSGNSB_Delta-C3_BHSGSB_Delta & $-1.577 \mathrm{~b}$ & 0.115 \\
C4_BHSGNSB_Delta-C4_BHSGSB_Delta & $-1.382 \mathrm{~b}$ & 0.167 \\
P3_BHSGNSB_Delta-P3_BHSGSB_Delta & $-1.186 \mathrm{~b}$ & 0.236 \\
P4_BHSGNSB_Delta-P4_BHSGSB_Delta & $-1.577 \mathrm{~b}$ & 0.115 \\
O1_BHSGNSB_Delta-O1_BHSGSB_Delta & $-.754 \mathrm{~b}$ & 0.451 \\
O2_BHSGNSB_Delta-O2_BHSGSB_Delta & $-2.233 \mathrm{~b}$ & 0.026 \\
F7_BHSGNSB_Delta-F7_BHSGSB_Delta & $-2.596 \mathrm{~b}$ & 0.009 \\
F8_BHSGNSB_Delta-F8_BHSGSB_Delta & $-2.400 \mathrm{~b}$ & 0.016 \\
T3_BHSGNSB_Delta-T3_BHSGSB_Delta & $-1.786 \mathrm{~b}$ & 0.074 \\
T4_BHSGNSB_Delta-T4_BHSGSB_Delta & $-2.037 \mathrm{~b}$ & 0.042 \\
T5_BHSGNSB_Delta-T5_BHSGSBB_Delta & $-2.107 \mathrm{~b}$ & 0.035 \\
T6_BHSGNSB_Delta-T6_BHSGSB_Delta & $-2.079 \mathrm{~b}$ & 0.038 \\
Fz_BHSGNSB_Delta-Fz_BHSGSB_Delta & $-.795 \mathrm{~b}$ & 0.426 \\
Cz_BHSGNSB_Delta-CZ_BHSGSB_Delta & $-1.591 \mathrm{~b}$ & 0.112 \\
Pz_BHSGNSB_Delta-Pz_BHSGSB_Delta & $-1.549 \mathrm{~b}$ & 0.121 \\
\hline \hline
\end{tabular}

$*$ BHSGSB: Breath holding with social bonding stimuli

*BHSGNSB: Breath holding with non social bonding stimuli

*Bold font: The significant channel in Delta wave

Researcher process the QEEG data using EEG Suite Insight II from Persyst to get the total value of each Delta, Theta, Alpha, Beta. Then using SPSS to analyze the statistic with $t$-test and if the data is not normal using non-parametric which is Wilcoxon Sign Rank Test.

\section{RESULTS}

After analyzing the data, the result is the data is not normal. Since then, researcher use Wilcoxon Sign Rank Test to compare Breath Holding with Social Bonding Stimuli and Breath 
Beta. The channel is significant if the value of $p<0,05$. From the statistic, the significant channel only located in slow wave, such as : Delta and Theta.

In Delta wave, the significant channel is on 02, F7, F8, T4, T5, T6, and Fz. While in Theta only significant in F7. From these result, we can conclude that in Delta and Theta wave, the value is significant on $\mathrm{O}$ in occipital, $\mathrm{F}$ in frontal and $\mathrm{T}$ in temporal lobe. Here is the result:

TABLE 2. The results of experiment in Theta wave

\begin{tabular}{|c|c|c|}
\hline & $\mathbf{Z}$ & Asymp. Sig. (2-tailed) \\
\hline Fp1_BHSGNSB_Theta-Fp1_BHSGSB_Theta & $-1.061 \mathrm{a}$ & 0.289 \\
\hline Fp2_BHSGNSB_Theta-Fp2_BHSGSB_Theta & $-.740 \mathrm{a}$ & 0.460 \\
\hline F3_BHSGNSB_Theta-F3_BHSGSB_Theta & $-1.158 a$ & 0.247 \\
\hline F4_BHSGNSB_Theta-F4_BHSGSB_Theta & $-.907 \mathrm{a}$ & 0.364 \\
\hline C3_BHSGNSB_Theta-C3_BHSGSB_Theta & $-1.172 \mathrm{a}$ & 0.241 \\
\hline C4_BHSGNSB_Theta-C4_BHSGSB_Theta & $-.321 \mathrm{a}$ & 0.748 \\
\hline P3_BHSGNSB_Theta-P3_BHSGSB_Theta & $-1.382 \mathrm{a}$ & 0.167 \\
\hline P4_BHSGNSB_Theta-P4_BHSGSB_Theta & $-.684 \mathrm{a}$ & 0.494 \\
\hline 01_BHSGNSB_Theta-01_BHSGSB_Theta & $-1.535 a$ & 0.125 \\
\hline O2_BHSGNSB_Theta-O2_BHSGSB_Theta & $-1.200 \mathrm{a}$ & 0.230 \\
\hline F7_BHSGNSB_Theta-F7_BHSGSB_Theta & $-2.107 \mathrm{a}$ & 0.035 \\
\hline F8_BHSGNSB_Theta-F8_BHSGSB_Theta & $-1.675 a$ & 0.094 \\
\hline T3_BHSGNSB_Theta-T3_BHSGSB_Theta & $-1.326 a$ & 0.185 \\
\hline T4_BHSGNSB_Theta-T4_BHSGSB_Theta & $-1.368 \mathrm{a}$ & 0.171 \\
\hline T5_BHSGNSB_Theta-T5_BHSGSBB_Theta & $-1.507 a$ & 0.132 \\
\hline T6_BHSGNSB_Theta-T6_BHSGSB_Theta & $-1.354 \mathrm{a}$ & 0.176 \\
\hline Fz_BHSGNSB_Theta-Fz_BHSGSB_Theta & $-1.102 \mathrm{a}$ & 0.270 \\
\hline Cz_BHSGNSB_Theta-Cz_BHSGSB_Theta & $-.907 a$ & 0.364 \\
\hline Pz_BHSGNSB_Theta-Pz_BHSGSB_Theta & $-1.298 \mathrm{a}$ & 0.194 \\
\hline
\end{tabular}

From the total value of Delta and Theta wave, the comparation of Breath Holding with Social Bonding Stimuli and Breath Holding with Non Social Bonding Stimuli are showed through the chart below:

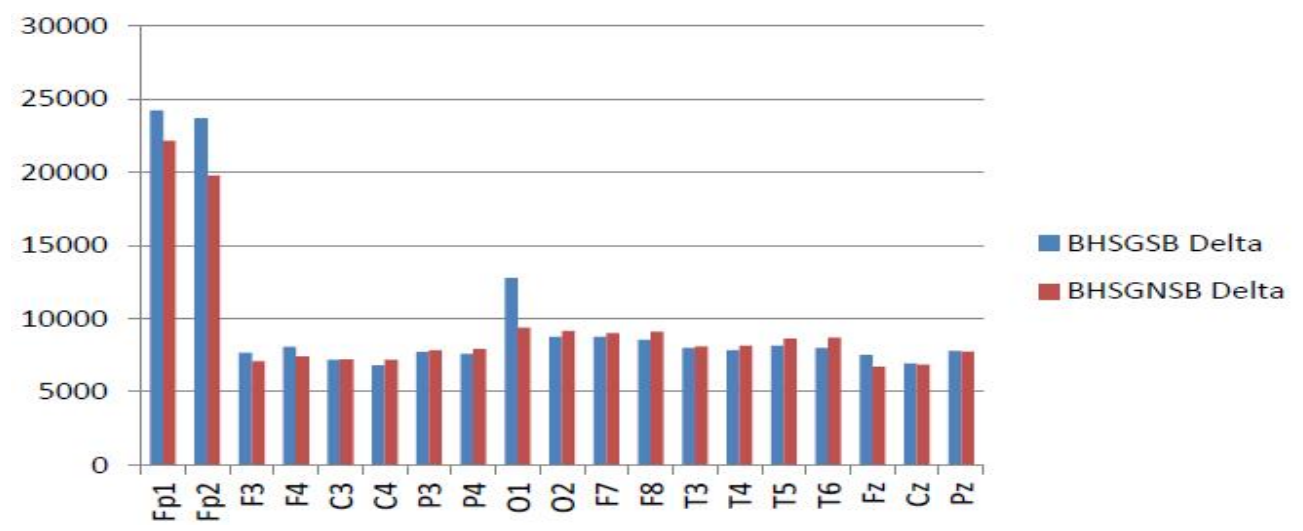

FIGURE 6. The comparison chart in Delta wave 
From the total value in Delta wave, we summarize the value into chart. In Delta wave, the significant channel is in 02, F7, F8, T4, T5, T6, Fz. In these channels, most of the chart of Breath Holding with Social Bonding Stimuli is lower than Breath Holding with Non Social Bonding Stimuli.

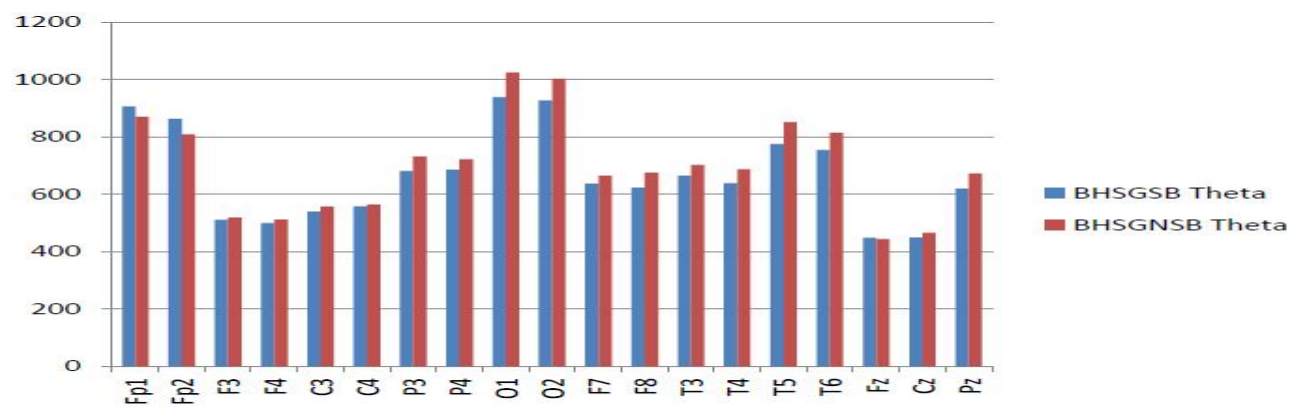

FIGURE 7. The comparison chart in Theta wave

In Theta wave, the significant channel is only in F7. In F7, the chart of Breath Holding with Social Bonding Stimuli is lower than Breath Holding with Non Social Bonding Stimuli. Also most of the chart of Breath Holding with Social Bonding Stimuli lower than the chart of Breath Holding with Non Social Bonding Stimuli.

These are the comparation of brain map spectrum which are recorded through EEG:
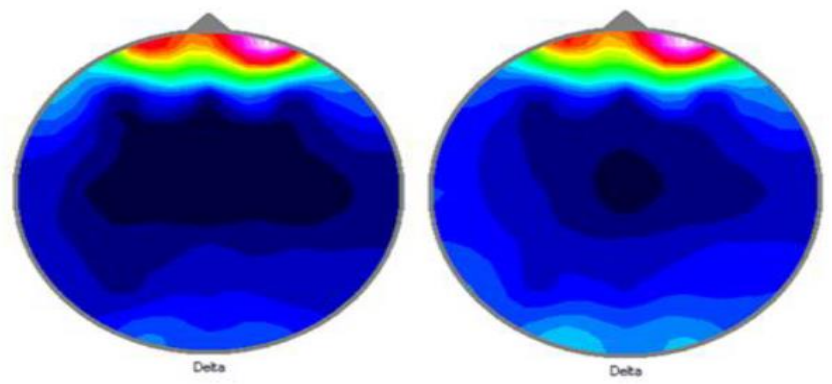

FIGURE 8 . 1) The comparation of brain map between social bonding stimuli without breath holding with breath holding with social bonding stimuli at Delta wave
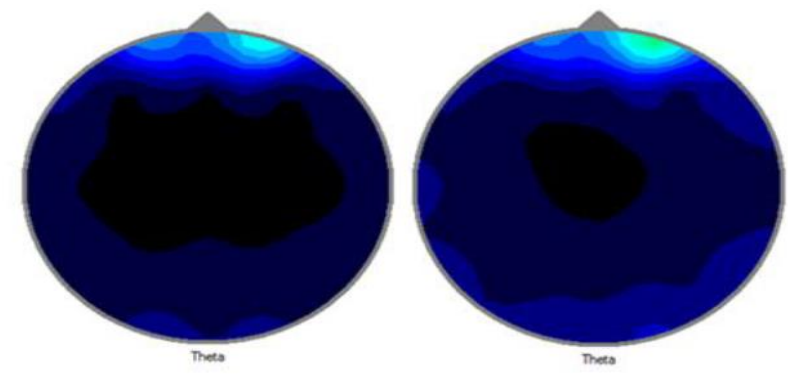

FIGURE 9 . 2) The comparation of brain map between social bonding stimuli without breath holding with breath holding with social bonding atimuli at Theta wave 

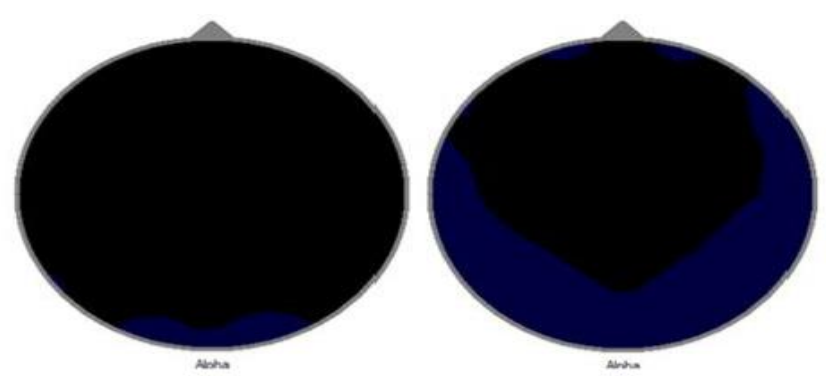

FIGURE 10 . 3) The comparation of brain map between social bonding stimuli without breath holding with breath holding with social bonding stimuli at Alpha wave
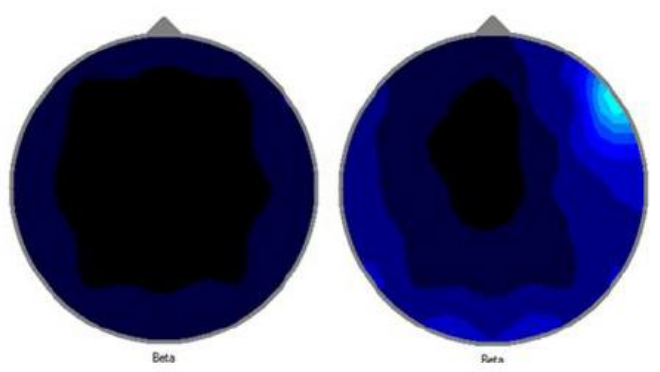

FIGURE 11 . 4) The comparation of brain map between social bonding stimuli without breath holding with breath holding with social bonding stimuli at Beta wave

\section{DISCUSSION AND CONCLUSION}

The channels are significant only in slow waves, Delta and Theta wave. Delta wave is in the state of unconscious mind where the deep sleep, deepest meditation, and dreamless sleep are located. Healing process are stimulated in this state. While Theta wave in the state of subconcious mind which are lead to intuition, learning, and memory. This is where human hold fears, trouble history, and nightmare. In Alpha wave, relaxation, visualization, creativity, and super learning are on this state. In Beta wave, brain is on the state of conscious mind where concentration, focus, and cognition are located. Memory and deepest meditation are saved in Delta and Theta wave and this is the reason why the brain channels are only significant in these two waves.

From the research, the significant channels of Delta and Theta wave is located on $0, \mathrm{~F}$, and $\mathrm{T}$ channel. Channel $\mathrm{O}$ is located on Occipital Lobes which is associated with interpreting visual stimuli and and information and located on the back part of the brain. Channel $\mathrm{F}$ is located on Frontal Lobes and associated with reasoning, planning, part of speech and movement, emotions, and problem solving. Channel $\mathrm{T}$ is located on Temporal Lobes and associated with perception, recognition of auditory stimuli, and memory. According to these functions of each lobes, all are associated with memory and emotions. And that is the reason why the datas are significant in these 3 channel and lobes. As we see from the chart, we get the data of the total value that Breath Holding with Social Bonding Stimuli is lower than Breath Holding with Non Social Bonding.

This is showed that panic emotions which are appeared as the result of breath holding intervention, can be reduced by Social Bonding Stimuli. This stimuli are showed by the photos of the family, bestfriend, and spouse. It gives the participants relaxation feeling to see their close relatives photos when they faced panic emotions inside the brain. The 
same work as opioid system which is act as a healing role in the human emotions. As the researcher still developing the research, there may some shortage in this research. EEG is very vulnerable with the movements outside the neuron, for example eye blinks, head movement, and any other movements. Participant who have panic disorder are not allowed in this research because if the participants have panic attacks, they will move their muscle and make the EEG record unstable. Replication are needed because the sample size of this research is small enough, about 39 participants.

\section{REFERENCES}

1. Pini S, Abelli M, Troisi A, Siracusano A, Cassano GB, Shear KM, Baldwin. The relationships among separation anxiety disorder, adult attachment style and agoraphobia in patients with panic disorder. Journal of Anxiety Disorders. 2014; 28(8): 741-746. DOI: 10.1016/j.janxdis.2014.06.010

2. La Pierre A. Part II: Affective and developmental neuroscience. The USA Body Psychoterapy Journal. 2005; 4(1): 1-21.

3. Mawson AR. Mass panic and social attachment: The dynamics of human behavior. Hampshire, UK: Ashgate Publishing Limited; 2007.

4. Mcdougall W. The group mind. London, UK: Cambridge University Press; 1920.

5. Lasswell HG. Propaganda and mass insecurity. Paper presented at: Army Medical Center, Washington, DC., WA; 1950.

6. Meerloo, J. Patterns of panic. New York, NY: International Universities Press; 1950.

7. Brosin HW. Panic states and their treatment. American Journal of Psychiatry. 1943; 100(1): 54-61. DOI: $10.1176 /$ ajp.100.1.54

8. L'Etang H. Some thoughts on panic in war. In Thursfield HG, Barclay CN. Yool WM, eds. Brassey's annual: The armed forces year book. London, UK: William Clowes \& Sons; 1966.

9. Battaglia M, Ogliari A, D’Amato F, Kinkead R. Early-life risk factors for panic and separation anxiety disorder: Insights and outstanding questions arising from human and animal studies of $\mathrm{CO}_{2}$ sensitivity. Neuroscience \& Biobehavioral Reviews. 2014; 46(3): 455-464. DOI: 10.1016/j.neubiorev.2014.04.005

10. Klein RG. Is panic disorder associated with childhood separation anxiety disorder? Clinical Neuropharmacol. 1995; 18; S7-S14. DOI: 10.1097/00002826-199518002-00003

11. Freire RC, Nardi AE. Panic disorder and the respiratory system: Clinical subtype and challenge tests. Revista Brasileira de Psiquiatria. 2012; 34, 32-41. DOI: 10.1016/S1516-4446(12)70053-3

12. Bowlby J. Maternal care and mental health. World Health Organization Monograph, Geneva, SW; 1951.

13. Panksepp J. Affective neuroscience: The foundations of human and animal emotion. New York, NY: Oxford University Press; 1998.

14. Sadock BJ, Sadock, VA. Panic disorder and agoraphobia in synopsis of psychiatry behavioral sciences/clinical psychiatry. Philadelphia, PA: Lippincott Williams \& Wilkins; 2007.

15. Shelton RC. Anxiety disorders. In Ebert M, Loosen P, Nurcombe B, Leckman J, eds. Current diagnosis \& treatment psychiatry. New York, NY: McGrawHill; 2008.

16. Taylor S. Anxiety sensitivity: Theoretical perspectives and recent findings. Behaviour Research and Therapy. 1995; 33(3): 243-258. DOI: 10.1016/0005-7967(94)00063-P

17. Han J, Park M, Hales RE. Anxiety disorders. In Robert M, Xiong MGL, Bourgeois J. eds. Lippincott's primary care psychiatry. Philadelphia, PA: Williams \& Wilkins; 2009.

18. Yaunin Y. Gangguan panik dengan agorafobia. Majalah Kedokteran Andalas. 36(2); 234-243: 2012.

19. Craske MG. Barlow DH. Mastery of your anxiety and panic. New York, NY: Oxford University Press; 1988.

20. Panksepp J. Textbook of biological psychiatry. New Jersey, NJ: Wiley-Liss, Inc; 2004.

21. Freire RC, Valença AM, Nascimento I, Lopes FL, Mezzasalma MA, Zin WA, Nardi AE. Clinical features of respiratory and nocturnal panic disorder subtypes. Psychiatry Research. 2007; 152(2): 287-291. D0I: 10.1016/j.psychres.2006.01.003 22. 
22. Abelson JL, Weg JG, Nesse RM, Curtis GC. Persistent respiratory irregularity in patients with panic disorder. Biological Psychiatry. 2001; 49(7): 588-595. DOI: 10.1016/S0006-3223(00)01078-7

23. Wilhelm FH, Gevirtz R, Roth WT. Respiratory dysregulation in anxiety, functional cardiac, and pain disorders. Assessment, phenomenology, and treatment. Behavior Modification. 2001; 25(4): 513-545. D0I: 10.1177/0145445501254003

24. Wilhelm FH, Roth WT. 2001. The somatic symptom paradox in DSM-IV anxiety disorders: Suggestions for a clinical focus in psychophysiology. Biological Psychology. 57(1); 105-140: 2001. D0I: 10.1016/S0301-0511(01)00091-6 25

25. Kinkead R, Tenorio L, Drolet G, Bretzner F, Gargaglioni L. Respiratory manifestations of panic disorder in animals and humans: A unique opportunity to understand how supramedullary structures regulate breathing. Respiratory Physiology \& Neurobiology. 204, 3-13; 2014. DOI: 10.1016/j.resp.2014.06.01326

26. Weems CF, Hammond-Laurence K, Silverman WK, Ferguson C. The relation between anxiety sensitivity and depression in children and adolescents referred for anxiety. Behaviour Research and Therapy. 1997; 35(10): 961-966. D0I: 10.1016/S0005-7967(97)00049-1

- This article does not have any appendix. - 